\title{
Spinal Fluid Lymphocytes Responsive to Autologous and Allogeneic Cells in Multiple Sclerosis and Control Individuals
}

\author{
G. Bimbaum, L. Kotilinek, M. Schwartz, and M. Sternad \\ Department of Neurology, University of Minnesota School \\ of Medicine, Minneapolis, Minnesota 55455
}

bstract. Spinal fluid lymphocytes from multiple sclerosis (MS) patients and controls were stimulated with either autologous non-T cells or with allogeneic non- $T$ cells followed by stimulation with autologous non-T lymphocytes. Cells responding to these stimuli were cloned and their proliferative responses to autologous and allogeneic MS and normal non-T cells were measured. Large numbers of clones with specific patterns of reaction to both autologous and allogeneic cells were obtained from lymphocytes in MS cerebrospinal fluid (CSF), but only occasionally from cells in control CSF. Patterns of responses among clones from a particular CSF were similar and often identical, which suggested that cells in MS CSF were relatively restricted in their specificities. Surface antigen phenotyping of the clones showed them to be predominantly OKT4+, with $13 \%$ OKT $8+$ and $11 \%$ OKT $4+8+$. Peripheral $T$ cells that were stimulated and cultured in parallel with CSF cells were different in that they usually did not give rise to as many clones nor were their patterns of response similar. Many CSF clones were heteroclitic, that is they responded to particular allogeneic cells but not autologous cells. Lymphocytes in MS CSF thus appear to represent a selected population of cells with a high frequency of responsiveness to autologous and allogeneic antigens. Such responses may be evidence for immune regulation within the central nervous system or could represent responses to altered-self antigens.

Portions of this work were presented in abstract form at the 1983 meetings of the Federation of American Societies of Experimental Biology and the American Academy of Neurology.

Received for publication 2 December 1983 and in revised form 1 May 1984.

J. Clin. Invest.

(c) The American Society for Clinical Investigation, Inc.

$0021-9738 / 84 / 10 / 1307 / 11 \quad \$ 1.00$

Volume 74, October 1984, 1307-1317

\section{Introduction}

Multiple sclerosis (MS) ${ }^{1}$ may be an autoimmune disease that results from or is associated with a persistent viral infection of the central nervous system (CNS) (1-4). Large numbers of lymphocytes are present within the CNS of patients, particularly in perivenular regions adjacent to areas of demyelination (5, 6). In addition, during acute exacerbations or with chronic active progression of the disease, a mononuclear cell pleocytosis is observed in the cerebrospinal fluid (CSF) $(7,8)$. The antigen(s) responsible for evoking these cellular responses is not known.

Several laboratories have characterized the lymphocytes found in the CSF of MS patients. Kam-Hansen et al. (9) and Naronha et al. (10) demonstrated that most of the cells in MS CSF were T cells and many were "activated" or in a state of DNA synthesis. Cashman et al. (11) and Hauser et al. (12) quantitated subpopulations of $\mathrm{T}$ lymphocytes in MS CSF and peripheral blood and correlated these with changes in clinical status. Merrill et al. (13) demonstrated loss of natural killer cell activity in MS CSF, which suggests that MS CSF lymphocytes may be different from cells seen in control CSF. Other laboratories have noted the presence of MS spinal fluid lymphocytes that are reactive to myelin basic protein (14), measles antigen (15), mitogens (16), and alloantigens (17). Thus, there are large numbers of immunocompetent cells in the CSF of MS patients, and these cells may be different than cells seen in the CSF of patients with other neurologic diseases.

Our experiments were designed to further investigate the specificity of lymphocytes in the CSF of MS patients. Our experiments were based on the following observations and hypotheses:

(a) Autologous major histocompatibility complex (MHC) antigens may be important in the pathogenesis of MS. Im-

1. Abbreviations used in this paper: allo-auto, allogeneic and autologous; auto-auto, autologous and autologous; CNS, central nervous system; CSF, cerebrospinal fluid; Il-2, Interleukin-2; MHC, major histocompatibility complex; MLR, mixed lymphocyte reaction; MS, multiple sclerosis; PBM, peripheral blood mononuclear cells; PHS, pooled human serum. 
munologic recognition of viral antigens is restricted by autologous MHC antigens (18). If the virus(es) associated with MS is a common one, and we feel, based upon other virally associated immune diseases, that this is most likely, then autologous antigens in MS patients may determine the development of the disease. In other words, the configuration of autologous antigens in MS may be such that their association with particular viral antigens results in an immune response crossreactive with CNS antigens. In support of this hypothesis are the observations that certain HLA phenotypes are associated with the illness (19). These genetic markers are not unique to MS patients, which suggests that they are linked to, but are not themselves, the MS susceptibility gene products.

In addition, cells responding to autologous antigens in an autologous mixed lymphocyte reaction (MLR) possess regulatory activity, demonstrating both helper (20) and suppressor function (21). The autologous MLR is increased in the peripheral blood of MS patients (22), and the presence of an autologous reaction in the CNS of patients with MS may be an important in situ regulatory mechanism.

(b) It has been well demonstrated in the mouse $(23,24)$ and in man (25) that cells recognizing hapten or viral-altered autologous antigens crossreact in an immunologically specific fashion with particular alloantigens. If an immune response to viral altered cells occurs in the CNS of MS patients it may be possible to detect such cells on the basis of their crossreactive responses to particular alloantigens.

To investigate whether responses to autologous and/or allogeneic antigens occurs in the CNS of MS patients we stimulated CSF lymphocytes from MS patients and controls with combinations of autologous and allogeneic non-T cells and measured the specificities of the responding cells at the clonal level. Clones responsive to autologous and allogeneic cells were demonstrated in the CSF of both MS patients and controls but in much greater numbers in cells from MS CSF. A restricted heterogeneity of response was noted within lymphocyte populations from individual CSF. Such restrictions were usually not noted when compared with analogous responses from peripheral blood lymphocytes, which suggests a compartmentalization of immune responses within the CNS. The large numbers of MS CSF cells responsive to alloantigens could represent responses to altered-self antigens.

\section{Methods}

Patients. 28 patients with probable or definite multiple sclerosis (26) were selected. Patients were in various phases of their disease, either acutely exacerbating, chronically progressive, or stable. None were on immunosuppressant medications when blood and CSF samples were obtained. Ages of the patients ranged from 16 to $50 \mathrm{yr}$ with a mean age of 36 yr. 23 of the patients were female.

Control patients consisted of 20 individuals who ranged in age from 21 to $78 \mathrm{yr}$. Their mean age was $47 \mathrm{yr}$. Eight of the controls were females. The neurologic diseases represented in the control group were dementias, stroke, multifocal paresthesias, post-myelography meningitis, post-viral transverse myelopathy, insulin-dependant diabetes mellitus with associated multifocal white matter disease, and viral meningitis. Cells from 11 control CSF were stimulated with autologous cells. Cells from seven control CSF were stimulated with allogeneic and autologous cells. Two control CSF had sufficient numbers of cells to allow them to be divided and stimulated with both protocols (CSF [57-58] and [62-63]).

Cerebrospinal fluids. Lumbar punctures were performed only for diagnostic or therapeutic reasons and patient permission was obtained to remove additional CSF. Fresh spinal fluid, $\sim 6-7 \mathrm{~cm}^{3}$, was gently centrifuged and the supernatant fluid was removed. The cell pellet was washed once with Hanks' balanced salt solution (Gibco Laboratories, Grand Island, NY) supplemented with $5 \%$ heat inactivated pooled, normal male human serum (PHS). Cells were resuspended in medium that consisted of RPMI 1640 (Gibco Laboratories), $20 \mathrm{mM}$ Hepes buffer (Gibco Laboratories), 10\% PHS, penicillin, and streptomycin. Cells were either used immediately or stored at $4^{\circ} \mathrm{C}$ overnight. Cells from one CSF were frozen and kept in liquid nitrogen for 1 wk before being used.

Peripheral blood mononuclear cells (PBM). Our procedures for the isolation of peripheral blood mononuclear cells (PBM) and the fractionation of PBM into $T$ and non-T-cell enriched populations have been described in detail (22). Briefly, PBM were obtained from heparinized peripheral blood by centrifugation on a Ficoll-Hypaque gradient. Cells were separated into $T$ and non- $T$ cells using a sheep erythrocyte rosetting technique. The $T$ and non- $T$ cell fractions were washed and resuspended in culture medium as above. The remaining PBM and unused T and non-T cell fractions were frozen and stored at $-80^{\circ} \mathrm{C}$ or in liquid nitrogen.

Stimulation of CSF lymphocytes. Three protocols were followed in stimulating CSF lymphocytes. In the first protocol, CSF lymphocytes were cultured for $7 \mathrm{~d}$ with irradiated $(3,000 \mathrm{rad})$, autologous non-T cells at a responder/stimulator ratio of 1:4. In the second protocol, CSF lymphocytes were stimulated with autologous non-T cells and cultured for $14 \mathrm{~d}$. Lymphocytes were washed, restimulated with irradiated autologous non-T cells at a responder/stimulator ratio of $1: 2$, and cultured for an additional $2 \mathrm{~d}$. The third protocol consisted of stimulating CSF lymphocytes with a pool of irradiated allogeneic PBM that was obtained from 10 unrelated patients with MS. The responder/ stimulator ratio was 1:2. Cultures were maintained for $14 \mathrm{~d}$. Lymphocytes were then washed and restimulated with autologous non-T cells for $2 \mathrm{~d}$ at a responder/stimulator ratio of 1:4.

Cells were cultured in V-bottom wells of 96-well tissue culture plates (Linbro Div, Flow Laboratories, Inc., McLean, VA), adding no more than 25,000 responder cells per well. Cultures were maintained at $37^{\circ} \mathrm{C}$ in a humidified atmosphere of $5 \% \mathrm{CO}_{2}$. In eight experiments, peripheral blood $\mathrm{T}$ cells from spinal fluid donors were stimulated concurrently in the same manner as their CSF lymphocytes. Numbers of peripheral blood $\mathrm{T}$ cells equivalent to those found in CSF were used.

Blast cell isolation. Blasts were obtained by centrifugation of cells for $10 \mathrm{~min}$ at $500 \mathrm{~g}$ on discontinuous Percoll (Pharmacia Fine Chemicals, Piscataway, NJ) gradients, using Percoll concentrations of 70 , $60,55,50,40$, and $20 \%$ (27). Cells at the $40 / 50 \%$ interface and the $50 / 55 \%$ interface were collected. These cells, consisting almost entirely of large cells, were washed in Hanks' balanced salt solution with 5\% PHS, and resuspended in cloning medium that consisted of culture medium as described above supplemented with an optimal concentration 
of Interleukin-2 (Il-2). Il-2 was prepared from peripheral blood lymphocytes as described in Inouye et al. (28).

Preparation of clones. The limiting dilution cloning techniques of Bach et al. (29) were used. Blast cells were innoculated into Terasaki 72-well tissue typing plates ("Histoplate", Cooke Laboratory Products, Alexandria, VA.) at a concentration of 3 cells/well. Feeder cells, which consisted of $1 \times 10^{4}$ irradiated (3,000 rad) autologous PBM, were also added to each well. Cultures were fed at 3-4-d intervals with fresh medium that contained Il-2. Wells were screened for the presence of clones 10-14 d after plating. Rapidly growing clones were transferred to flat-bottom 96-well tissue culture plates (Linbro Div., Flow Laboratories, Inc.) with fresh medium that contained Il-2 and $1 \times 10^{5}$ feeder cells. Less rapidly growing clones were discarded. As numbers of clone cells increased they were transferred to flat bottom $16-\mathrm{mm}$ diameter wells in 24-well tissue culture plates (Linbro Div., Flow Laboratories, Inc.) with fresh medium and $2 \times 10^{5}$ feeder cells. Feeder cells were added to clones once per week. Clones were assayed for immunological reactivity when $>2 \times 10^{5}$ cells were present. Fewer plates for cloning were set up with cells from control CSF. This was not due to fewer numbers of cells present in control cultures. Rather, this reflected the decreased numbers of blast cells that were obtainable from the Percoll gradients after autologous and allogeneic stimulation.

We use the term "clone" advisedly. The clonality of our cells has not been proven. We attempted to replate clones at cell concentrations of $<1$ cell/well but were unsuccessful. Our use of the term "clone" must therefore be viewed in the more general sense, that is in terms of a high probability of our cultures being clones or at least highly restricted colonies of responding cells.

Surface antigen phenotyping. Surface antigen phenotyping of the clones was determined with the use of the monoclonal anti-T cell antibodies OKT3, OKT4, and OKT8 (Ortho Diagnostic Systems, Inc., Raritan, NJ), fluoresceinated rabbit anti-mouse gamma globulin, and a flourescence-activated cell sorter (Ortho Diagnostic System Inc., Westwood, MA). Cells were incubated with appropriate dilutions of the monoclonal antibodies for $30 \mathrm{~min}$ at $4^{\circ} \mathrm{C}$. Cells were washed and reincubated with an optimal dilution of the fluoresceinated rabbit antimouse gamma globulin for $30 \mathrm{~min}$ at $4^{\circ} \mathrm{C}$.

Histocompatibility typing. Cells from patients, controls, and panel cell donors were HLA-A,B,C, and DR typed in the Tissue Typing Laboratory of the University of Minnesota Hospitals.

Assay of immunological reactivity. Clone proliferation in response to stimulation with a panel of autologous and allogeneic non-T cells was used as a measure of immune responsiveness. Il-2 was omitted from culture during the assays and assays were performed 3-4 $d$ after feeding with Il-2-containing medium. 5,000 washed clone cells were added to each conical-bottom well of a 96-microwell plate. Cells were stimulated in triplicate for $48 \mathrm{~h}$ with 25,000 irradiated (3,000 rad) stimulator cells. Stimulator cells were peripheral blood non-T cells obtained from the spinal fluid donor, patients with definite MS, and normal individuals. MS and control cells were matched as closely as possible for HLA-DR phenotype. The same panel was used within each experiment, but panels differed between assays. Responder cells cultured without stimulator cells were used to determine background $\left[{ }^{3} \mathrm{H}\right]$ thymidine incorporation. After $40 \mathrm{~h}$ incubation, cultures were pulsed for $8 \mathrm{~h}$ with $2 \mu \mathrm{Ci}$ per well of tritiated thymidine, specific activity $20 \mathrm{Ci} / \mathrm{mM}$ (New England Nuclear, Boston, MA). Cells were harvested onto fiberglass filter paper using a multisample cell harvester. Incorporated radioactivity was measured in a liquid scintillation counter.

Stimulatory capacity of panel cells. To ensure that all panel cells had equivalent stimulatory capacities, panel cells were used as stimulators in a one way mixed lymphocyte culture system using normal, alloantigen pool-primed cells as responders (30). All cells in our panels had equivalent stimulatory capacities.

Reproducibility of assay results. To determine the reproducibility of our clone responses 20 clones were reassayed using the original panels of stimulator cells. Clones had been stored in liquid nitrogen and were cultured for $7 \mathrm{~d}$ with II-2 before reassay. In almost all instances the proliferative responses of frozen-thawed clones were lower than fresh clones. However, the patterns of response were the same between fresh and frozen clones, which demonstrated the reproductibility of their responses.

Statistical methods. A clone was considered responsive to a particular panel cell if the counts per minute (cpm) $\left[{ }^{3} \mathrm{H}\right]$ thymidine incorporated were either three times background $\mathrm{cpm}$ or were $>1,000 \mathrm{cpm}$. The more rigorous criterion was always used. Since the great majority of background $\mathrm{cpm}$ from unstimulated clones were $<300 \mathrm{cpm}$, most "positive" clones had cpm greater than four times background. In addition, standard deviations were almost always $<30 \%$ and usually $10-20 \%$. No "feeder" effects were noted, that is the amount of $\left[{ }^{3} \mathrm{H}\right]$ thymidine incorporated by clone cells cultured with nonstimulating panel cells were the same or lower than the amounts of radioisotope that were incorporated by clone cells cultured alone. Differences between lymphocyte populations were determined by the use of the paired and unpaired $t$ tests and by Chi square analysis.

\section{Results}

Numbers of spinal fluid lymphocytes in MS and control subjects. There were wide variations in numbers of cells obtained from CSF samples. In patients with chronically progressive or static MS, as few as $5-10,000$ cells $\left(0-2\right.$ cells $\left./ \mathrm{mm}^{3}\right)$ were collected in $6-7 \mathrm{~cm}^{3}$ of CSF, while up to 200,000 cells $\left(30\right.$ cells $/ \mathrm{mm}^{3}$ ) were collected from patients with active, acute MS. Most MS patients had between $30-50,000$ cells $\left(4-7\right.$ cells $\left./ \mathrm{mm}^{3}\right)$ in their CSF sample. Most control CSF had between 10 and 20,000 cells $\left(0-2\right.$ cells $\left./ \mathrm{mm}^{3}\right)$. Patients with CNS inflammatory diseases had up to $2 \times 10^{6}$ cells $\left(300\right.$ cells $\left./ \mathrm{mm}^{3}\right)$ in their CSF samples. The responsiveness of cells from MS patients in our cultures was related to disease activity as well as the numbers of cells present in their CSF. Cells from acutely exacerbating patients were much more responsive to both allogeneic and autologous stimulation.

Reactivity of spontaneous blast cells. To determine whether in vivo activated cells from fresh MS spinal fluid respond to autologous or allogeneic cells, blast cells from five freshly collected MS CSF were collected on discontinuous Percoll gradients and cloned without prior in vitro stimulation. A total of 104 clones were assayed against autologous non-T cells and a panel of allogeneic MS and control cells. Only one clone demonstrated low levels of proliferative response to both autologous cells and to one allogeneic normal panel member's cells. Thus, very small numbers of in vivo generated blast cells appear to be responsive to autologous or allogeneic antigens.

Autologous stimulation of spinal fluid lymphocytes. The presence of autologously reactive cells in MS spinal fluid could 
be evidence of immune regulation within the CNS of these patients $(20,21)$. We looked for the presence of such cells in MS and control CSF by stimulating fresh spinal fluid lymphocytes with autologous non-T cells. Using the two stimulation protocols described, many more clones were obtained from the lymphocytes of MS CSF than from lymphocytes of control CSF (Tables I and II). The one MS CSF from which no clones were obtained had been frozen before being cultured. A total of 275 clones were assayed from MS CSF, using the autologous and autologous (auto-auto) stimulation protocol. Representative values that were obtained from responding clones are shown in Table III.

The specificities of clones that were derived from autologously stimulated CSF are shown in Table IV. 107 of the 154 reactive clones from MS CSF responded to autologous cells with or without concommitant responses to allogeneic cells. While the percentage of reactive clones was similar in control CSF (22 of 56), only two of these responded to autologous cells. The majority (36 of 56) of control clones came from the CSF of one individual. This patient, while not having MS, did

Table I. Single Autologous Stimulation of Spinal Fluid Lymphocytes*

\begin{tabular}{cccl}
\hline MS & & & \\
\hline CSF number & Plates & Clones assayed & Responsive clones \\
\hline 7 & 10 & 13 & 2 \\
9 & 12 & 12 & 4 \\
11 & 10 & 5 & 1 \\
12 & 12 & 6 & 1 \\
13 & 7 & 27 & 6 \\
14 & 12 & 23 & 7 \\
19 & 14 & 17 & 1 \\
Control & & & \\
\hline 20 & 3 & 7 & 0 \\
31 & 2 & $0 \S$ & - \\
34 & 3 & 19 & 1 \\
42 & 11 & $0 \S$ & - \\
46 & 2 & 5 & - \\
47 & 3 & $0 \S$ & - \\
48 & 2 & 12 & 1 \\
39 & 5 & $0 \S$ & \\
\hline
\end{tabular}

* Spinal fluid lymphocytes were cultured with autologous non-T cells for $6 \mathrm{~d}$. Blast cells were isolated on Percoll gradients and cloned at cell concentrations of three cells per well. Clones were expanded using II-2. Proliferative responses to autologous and alloantigens were measured by culturing clones in the absence of Il-2 with autologous or allogeneic non-T cells from MS and controls.

$¥$ Numbers of microwell plates seeded at time of limiting dilution culture.

$\S$ No clones obtained.
Table II. Auto-Auto Stimulation of Spinal Fluid and Peripheral Blood Lymphocytes*

\begin{tabular}{llll}
\hline MS & & & \\
\hline CSF number & Plates & Clones assayed & Responsive clones \\
\hline 44 & 16 & 36 & 4 \\
45 & 2 & 10 & 1 \\
54 & 16 & 49 & 20 \\
55 & $6(2) \S$ & $53(18)$ & $49(3)$ \\
56 & $2(2)$ & $11(1)$ & $2(0)$ \\
61 & $12(12)$ & $41(18)$ & $23(13)$ \\
65 & $14(6)$ & $11(15)$ & $3(13)$ \\
66 & 10 & 12 & 7 \\
69 & $12(4)$ & $52(8)$ & $45(2)$ \\
70 & 3 & 0 & - \\
Control & & & \\
\hline 43 & 1 & 0 & - \\
52 & Nonell & - & - \\
$59 \pi$ & 10 & 36 & 1 \\
58 & 12 & 3 & $0(2)$ \\
63 & $14(6)$ & $17(20)$ & \\
\hline
\end{tabular}

* CSF lymphocytes were cultured for $14 \mathrm{~d}$ with autologous non- $\mathrm{T}$ cells and then restimulated with fresh autologous non-T cells. After $2 \mathrm{~d}$ blast cells were isolated and cloned at limiting dilution. Assays were performed as described in Table $I$.

$\ddagger$ Numbers of microwell plates seeded at time of limiting dilution assay.

$\S$ Numbers in parentheses represent results obtained with peripheral blood $\mathrm{T}$ cells from CSF donors

"No blast cells were recovered after stimulation with autologous nonT cells.

I Patient A. See Appendix for a brief clinical summary.

have a neurologic disease that was similar in several ways to MS. A brief clinical summary of this patient (patient A) is presented in the Appendix. Two control patients had large numbers of lymphocytes in their spinal fluids. One patient had viral meningitis (CSF 63). The other had CSF pleocytosis 4 wk after oil contrast myelography (CSF 58). Neither of these CSF samples generated more than one clone. Thus, responses to both autologous and allogeneic cells could be demonstrated in CSF lymphocytes from MS patients and controls but in greater numbers from the CSF of MS patients. The higher frequency of responses was not the result of greater numbers of cells in MS CSF.

Limited heterogeneity of responses of autologously stimulated clones. Five MS CSF and one control CSF (59) had sufficient numbers of responsive clones per CSF to allow us to determine whether recurring patterns of response occurred among clones from individual CSF. In addition, we correlated the patterns of response with the HLA-DR phenotypes of the 
Table III. Proliferative Responses of Cloned T Cells Derived from Autologously Stimulated Cultures of MS Spinal Fluid*

\begin{tabular}{|c|c|c|c|c|}
\hline $\begin{array}{l}\text { CSF } \\
\text { number }\end{array}$ & Panel & Clone $7(371) \ddagger$ & & \\
\hline \multirow[t]{11}{*}{54} & Autologous & $10,627 \pm 1,633 \S$ & & \\
\hline & MS 2 & $144 \pm 27$ & & \\
\hline & MS 3 & $185 \pm 56$ & & \\
\hline & MS 4 & $120 \pm 47$ & & \\
\hline & MS 5 & $430 \pm 28$ & & \\
\hline & Normal 1 & $354 \pm 64$ & & \\
\hline & Normal 2 & $324 \pm 20$ & & \\
\hline & Normal 3 & $363 \pm 11$ & & \\
\hline & Normal 4 & $396 \pm 25$ & & \\
\hline & Normal 5 & $441 \pm 34$ & & \\
\hline & & Clone 29(184) & Clone 33(297) & Clone 42(104) \\
\hline \multirow[t]{11}{*}{55} & Autologous & $2,251 \pm 112$ & $5,495 \pm 342$ & $5,260 \pm 159$ \\
\hline & MS 2 & $103 \pm 17$ & $341 \pm 42$ & $96 \pm 41$ \\
\hline & MS 3 & $132 \pm 69$ & $457 \pm 45$ & $149 \pm 38$ \\
\hline & MS 4 & $7,627 \pm 373$ & $22,180 \pm 2,947$ & $9,412 \pm 1,290$ \\
\hline & MS 5 & $231 \pm 67$ & $691 \pm 128$ & $216 \pm 41$ \\
\hline & Normal 1 & $232 \pm 90$ & $229 \pm 25$ & $127 \pm 29$ \\
\hline & Normal 2 & $515 \pm 103$ & $845 \pm 43$ & $131 \pm 10$ \\
\hline & Normal 3 & $4,272 \pm 250$ & $9,379 \pm 491$ & $7,942 \pm 482$ \\
\hline & Normal 4 & $4,199 \pm 79$ & $11,652 \pm 365$ & $7,682 \pm 630$ \\
\hline & Normal 5 & $87 \pm 11$ & $429 \pm 175$ & $127 \pm 78$ \\
\hline & & Clone 26(73) & Clone 28(99) & \\
\hline \multirow[t]{10}{*}{69} & Autologous & $10,508 \pm 514$ & $11,008 \pm 246$ & \\
\hline & MS 2 & $103 \pm 12$ & $139 \pm 4$ & \\
\hline & MS 3 & $20,928 \pm 1426$ & $24,837 \pm 1,225$ & \\
\hline & MS 4 & $22,329 \pm 750$ & $25,013 \pm 605$ & \\
\hline & MS 5 & $235 \pm 47$ & $207 \pm 27$ & \\
\hline & Normal 1 & $13,185 \pm 372$ & $19,305 \pm 847$ & \\
\hline & Normal 2 & $12,779 \pm 1,438$ & $21,242 \pm 1,204$ & \\
\hline & Normal 3 & $215 \pm 22$ & $217 \pm 66$ & \\
\hline & Normal 4 & $90 \pm 3$ & $216 \pm 20$ & \\
\hline & Normal 5 & $148 \pm 8$ & $119 \pm 27$ & \\
\hline
\end{tabular}

* Cloned $\mathrm{T}$ cells $\left(5 \times 10^{3} /\right.$ well) were cultured for $48 \mathrm{~h}$ with non-T cells $(2.5$ $\times 10^{4} /$ well). Cultures were pulsed with $\left[{ }^{3} \mathrm{H}\right]$ thymidine for $8 \mathrm{~h}$ before harvest. ‡ Counts per minute $\left[{ }^{3} \mathrm{H}\right]$ thymidine incorporated by clone cells cultured alone. $\S$ Counts per minute $\left[{ }^{3} \mathrm{H}\right]$ thymidine incorporated \pm SD.

responding and stimulating cells. We chose DR antigens for comparison since the great majority of our clones were OKT4+ and cells of this phenotype have been reported to respond predominantly to class II antigens (31). Recurring patterns of response within individual CSF were seen among clones of four of the five MS CSF $(54,55,66,69)$ but not among any of the 21 clones from the control CSF. The recurring patterns of clone responses from MS CSF 55 are shown in Table III and Fig. 1. There was no DR identity between responder cells and any of the panel cells evoking a response. In MS CSF 69, 23 of 45 responding clones had an identical pattern of response, with an additional 11 clones having very similar patterns that differed by only one panel member. In this assay, almost all
Table IV. Numbers of Lymphocyte Clones from Autologously Stimulated Spinal Fluid and Peripheral Blood Responding to Autologous and Allogeneic Cells

\begin{tabular}{|c|c|c|c|c|c|}
\hline \multicolumn{6}{|l|}{ MS } \\
\hline \multirow[b]{3}{*}{$\begin{array}{l}\text { Original } \\
\text { stimulators }\end{array}$} & \multicolumn{3}{|c|}{$\begin{array}{l}\text { Numbers of clones } \\
\text { responding to }\end{array}$} & \multirow{2}{*}{\multicolumn{2}{|c|}{$\begin{array}{l}\text { Number of } \\
\text { responses to* }\end{array}$}} \\
\hline & \multirow[b]{2}{*}{$\begin{array}{l}\text { Autologous } \\
\text { cells only }\end{array}$} & \multirow[b]{2}{*}{$\begin{array}{l}\text { Allogeneic } \\
\text { cells only }\end{array}$} & \multirow{2}{*}{$\begin{array}{l}\text { Autologous } \\
\text { and } \\
\text { allogeneic } \\
\text { cells }\end{array}$} & & \\
\hline & & & & MS cells & $\begin{array}{l}\text { Normal } \\
\text { cells }\end{array}$ \\
\hline Autologous & 2 & 14 & 6 & 25 & 35 \\
\hline Auto-Auto & $15(13) \ddagger$ & 47 (13) & $92(7)$ & $301(39)$ & $268(21)$ \\
\hline \multicolumn{6}{|l|}{ Control } \\
\hline Autologous & 1 & 1 & 1 & 3 & 2 \\
\hline Auto-Auto & $0(0) \ddagger$ & $20(0)$ & $2(2)$ & $26(3)$ & $19(2)$ \\
\hline
\end{tabular}

* Proliferative responses to cells from MS patients or normal individuals. Since one clone could respond to more than one panel cell, numbers of responses are greater than numbers of responding clones.

$\ddagger$ Numbers in parentheses indicate results obtained with peripheral blood $\mathrm{T}$ cells from CSF donors.

panel cells that evoked responses shared one DR haplotype with the responding cell donor (DR 2 or 3). Thus, these data demonstrate restricted, recurrent patterns of response among clones that were derived from individual MS CSF, which suggests that these cells represent a population of limited heterogeneity. In addition, responses frequently did not correlate with the sharing of serologically determined HLA-DR phenotypes between stimulators and responders.

Comparison of peripheral and CSF lymphocyte responses. Immune responses within the CNS appear to be compartmentalized and different from those noted in peripheral blood (13, 32-34). To investigate this in our system, T cells were obtained from the peripheral blood of five MS CSF donors and one control CSF donor. These cells were cultured in identical numbers and in an identical fashion to autologous spinal fluid lymphocytes. Results are presented in Tables II and IV. In all instances but one, differences between the two cell populations were noted both in the numbers of clones that were obtained

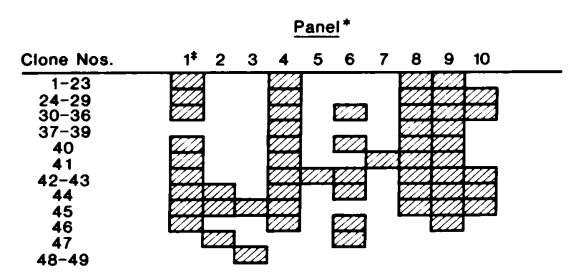

Figure 1. Response patterns of clones from autologously stimulated lymphocytes from an MS spinal fluid (\#55). ${ }^{* 1-5}$ are cells from MS patients. 6-10 are cells from normal individuals. ¥Autologous cells. 
and the patterns of responses. Only peripheral $\mathrm{T}$ cell clones from the donor of MS CSF 65 showed a pattern similar to that seen with clones from autologous CSF lymphocytes. Thus, with the exception of CSF 65, clones that were obtained from the peripheral blood of MS patients differed both quantitatively and qualitatively from clones that were obtained from autologous CSF, which supports the concept that immune responses in CNS are compartmentalized.

Allogeneic and autologous stimulation of spinal fluid lymphocytes. To obtain a diversity of alloantigens, we stimulated our spinal fluid lymphocytes with a pool of peripheral blood lymphocytes from 10 unrelated patients with MS. To select for those alloantigen reactive cells crossreactive with alteredself antigens, cultures were restimulated $14 \mathrm{~d}$ later with autologous non-T cells. Implicit in this protocol was the assumption that altered self antigens may be present on peripheral blood lymphocytes. Observation in persistent CNS viral infections of animals (35) and man (36) support this assumption.

Table V. Allo-Auto Stimulation of Spinal Fluid and Peripheral Blood Lymphocytes*

\begin{tabular}{llcc}
\hline MS & & & \\
\hline CSF number & Plates & $\begin{array}{l}\text { Clones } \\
\text { assayed }\end{array}$ & $\begin{array}{c}\text { Reactive } \\
\text { clones }\end{array}$ \\
\hline 27 & 20 & 57 & 13 \\
28 & 32 & 104 & 38 \\
30 & 20 & 43 & 2 \\
33 & 20 & 22 & 3 \\
37 & 16 & 80 & 35 \\
Control & & & \\
\hline 29 & None§ & - & - \\
38 & 4 & 1 & - \\
41 & 3 & 0 & - \\
50 & None & - & - \\
51 & 2 & 0 & 1 \\
57 & 12 & 7 & $1(2)$ \\
62 & $14(6)^{\prime \prime}$ & $26(14)$ & - \\
$64 \pi$ & $14(6)$ & $38(4)$ & \\
67 & None & - & \\
\hline
\end{tabular}

* Spinal fluid lymphocytes were cultured for $14 \mathrm{~d}$ with a pool of allogeneic PBM that was obtained from 10 unrelated patients with MS. Cells were then restimulated with autologous non-T cells. $2 \mathrm{~d}$ later, blast cells were isolated on discontinuous Percoll gradients. Cells were cloned and assayed as described in Table I.

$¥$ Numbers of microwell plates seeded at time of limiting dilution culture.

$\S$ No cells recovered after allogeneic stimulation.

"Numbers in parentheses represent results obtained with peripheral T cells from the CSF donor.

I Patient B. See Appendix for brief clinical summary.
Table VI. Proliferative Responses of Cloned $T$ Cells Derived from Allo-Auto Stimulated Cultures of MS Spinal Fluid Lymphocytes*

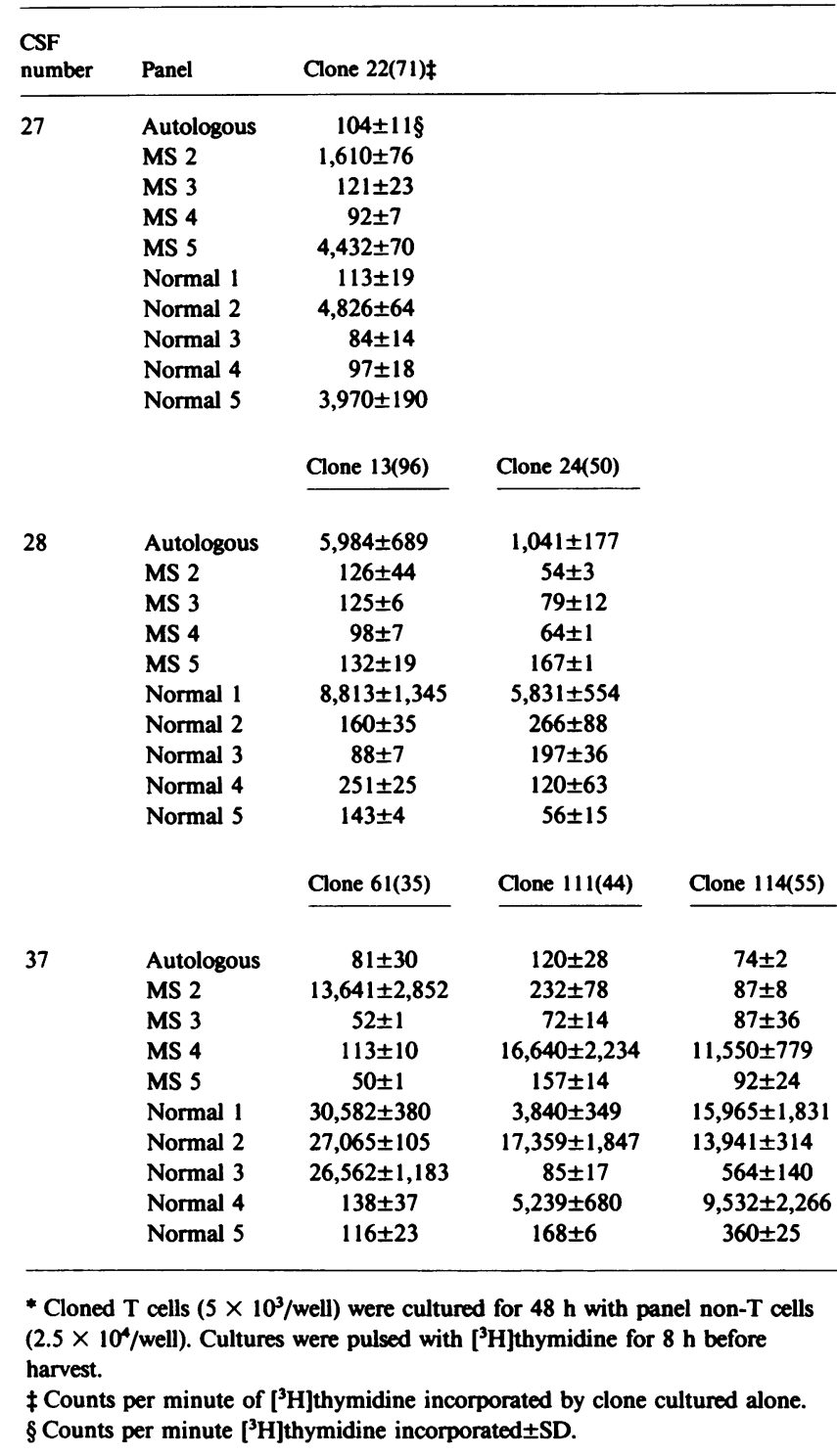

Spinal fluid lymphocytes from five MS patients and nine control patients were allo-auto stimulated. Numbers of clones obtained are shown in Table V. Representative clonal responses are presented in Table VI. The specificities of their responses are shown in Table VII. Most of the clones from control CSF were from CSF 64. While this patient did not have MS, aspects of his neurologic disease were very similar to patients with MS. A brief clinical description of this patient is given in the Appendix (patient B). With the exception of this patient's CSF, lymphocytes from MS CSF were more responsive to allo-auto stimulation than were cells from control CSF. 
Table VII. Number of Lymphocyte Clones from Allo-Auto Stimulated Spinal Fluid and Peripheral Blood Responding to Autologous and Allogeneic Cells

\begin{tabular}{|c|c|c|c|c|}
\hline \multicolumn{5}{|l|}{ MS } \\
\hline \multicolumn{3}{|c|}{ Number of clones responding to } & \multicolumn{2}{|c|}{ Number of responses to } \\
\hline $\begin{array}{l}\text { Autologous } \\
\text { cells only }\end{array}$ & $\begin{array}{l}\text { Allogeneic } \\
\text { cells only }\end{array}$ & $\begin{array}{l}\text { Autologous } \\
\text { and } \\
\text { allogeneic cells }\end{array}$ & $\begin{array}{l}\text { MS } \\
\text { cells }\end{array}$ & $\begin{array}{l}\text { Normal } \\
\text { cells }\end{array}$ \\
\hline 5 & 71 & 15 & 62 & $131 \dagger$ \\
\hline \multicolumn{5}{|l|}{ Control } \\
\hline $2(0) \S$ & $6(2)$ & $5(0)$ & $10(2)$ & $18(3)$ \\
\hline
\end{tabular}

* Proliferative responses to cells from MS patients or normal individuals. Since one clone could respond to more than one panel cell, numbers of responses are greater than numbers of responding clones. $\dagger$ Difference between MS and normal responses statistically significant $(P<0.0001)$.

$\S$ Numbers in parentheses indicate values obtained with peripheral blood $\mathrm{T}$ cells from the CSF donors.

Patterns of responses from allogeneic-autologous stimulated clones. The majority of the clonal responses from allo-auto stimulated CSF clones were heteroclitic, that is they responded to allogeneic cells but not to autologous cells (Table VII). Responses to MS panel cells were considerably less frequent than responses to control panel cells (62 vs. 131), a difference that is statistically significant at the $P<0.0001$ level. Clones from control CSF responded to MS and control allogeneic panel cells with equal frequency.

Limited heterogeneity of allo-auto stimulated clone responses. Three of the five MS CSF $(27,28,37)$ and one of the control CSF (CSF 64) had sufficient numbers of responsive clones to recurring patterns of responses within individual CSF. Clones from two of the three MS CSF (28 and 37) and from the control CSF showed such recurring patterns. Fig. 2 illustrates the patterns seen with clones from MS CSF 37 and from control CSF 64. Thus, clones from allo-auto stimulated CSF demonstrated restricted, recurring patterns of proliferation, an observation similar to that noted with autologously stimulated CSF cells.

The DR phenotypes of the CSF cells were compared with those of the panel cells. In some instances, clonal response patterns correlated with shared panel DR phenotypes. In other instances patterns could not be explained on this basis. In CSF 28 , only one panel member shared a DR haplotype with the responder (DRw6). 11 of 38 clones responded to autologous cells and to this panel member's cells. In the remaining 27 clones, the observed proliferative responses did not follow any shared DR pattern. In CSF 37, six of the panel cells shared a DR phenotype with the responder (either DR 1 or 4 ) and patterns of proliferation only partially correlated with the

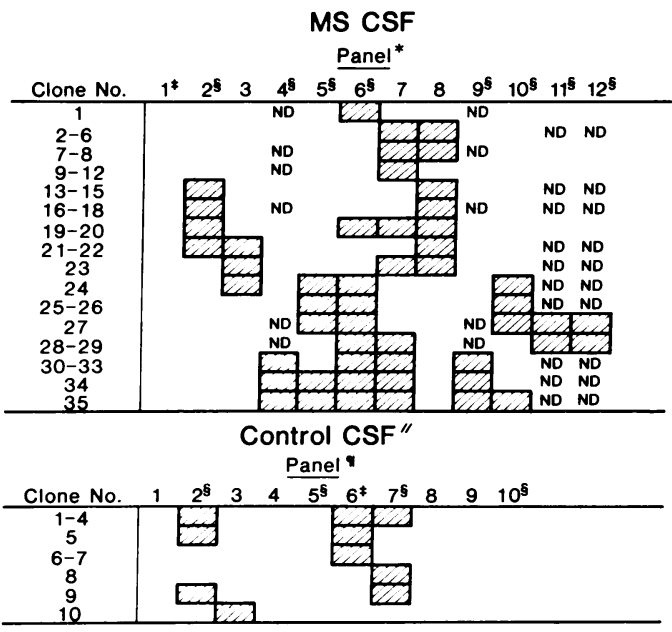

Figure 2. Response patterns of allo-auto stimulated spinal fluid lymphocyte clones. ${ }^{*} 1-5$ and 11 are cells from MS patients. 6-10 and 12 are cells from normal individuals. $\ddagger$ Autologous cells. §Panel members sharing DR type with the autologous stimulator. "Patient B. See Appendix for brief clinical summary. $\$ 1-5$ are cells from MS patients. 7-10 are cells from normal individuals.

sharing of DR antigens (Fig. 2). A similar situation was noted with control CSF 64 . The proliferative responses of CSF clones thus corresponded with shared responder/stimulator DR phenotypes in some instances. In other instances, no such correlation was observed.

Comparison of peripheral and CSF lymphocyte responses. In two experiments, using control CSF 62 and 64, responses of peripheral blood $\mathrm{T}$ cells were compared with autologous CSF cells. Results are shown in Table V. These data, while limited, are in agreement with our observations on autologously stimulated peripheral and CSF lymphocytes, that lymphocyte populations within the CSF differ both quantitatively and qualitatively from those seen in peripheral blood.

Surface antigen phenotypes of clones. 44 clones were tested for surface antigen phenotypes using the monoclonal antibodies OKT3, OKT4, and OKT8. 38 of the clones were derived from MS CSF; two were from control CSF; and four were derived from the peripheral blood of an MS patient. Table VIII lists the phenotypes of the clones as well as their patterns of reaction. All clones reacted with OKT3 antibody, which indicated that they were mature $T$ cells. Of particular interest are the $11 \%$ of clones from MS CSF that were both OKT4+8+. It is unlikely that these represented nonclonal mixtures of cells, since each of the percentages from OKT4+ and OKT8+ were $>75 \%$, and in two instances $>90 \%$.

\section{Discussion}

We have successfully cultured and cloned lymphocytes from spinal fluids of MS and control individuals and have demon- 
Table VIII. Surface Antigen Phenotypes of Lymphocyte Clones from MS and Control Patients*

\begin{tabular}{llll}
\hline Donor & Origin & Phenotype & Reactivity \\
\hline MS & CSF & OKT4+ $(76 \%)$ & $\begin{array}{l}72 \% \text { Alloreactive } \\
3 \% \text { Allo \& auto reactive } \\
\end{array}$ \\
& & & $3 \%$ Autologously reactive \\
MS & CSF & OKT8+ $(13 \%)$ & $100 \%$ Alloreactive \\
MS & CSF & OKT4+8+(11\%) & $25 \%$ Alloreactive \\
& & & $25 \%$ Autoreactive \\
& & & $25 \%$ Allo \& auto reactive \\
MS & blood & OKT4+ $(100 \%)$ & $25 \%$ Alloreactive \\
& & & $50 \%$ Allo \& auto reactive \\
OND & CSF & OKT4+ & $100 \%$ Nonreactive
\end{tabular}

* Clones from MS CSF 28, 33, 37, 44, 61, and 69, and from control CSF 34 and 48 were labeled with the monoclonal antibodies OKT3, OKT4, and OKT8. Cells were then stained with rabbit anti-mouse gamma globulin. The patterns of cell staining were determined with a fluorescence-activated cell sorter.

¥ The difference between the sum of the percentages listed and $100 \%$ is the percentage of nonreactive clones.

OND, other neurologic diseases.

strated that large numbers of cells in some MS spinal fluid are reactive to autologous and allogeneic antigens. We have also demonstrated that there are restricted, recurring patterns of response among clones from individual CSF, and that these patterns are different from those obtained with peripheral blood lymphocytes. In addition, frequent heteroclitic responses to normal allogeneic lymphocytes were noted, despite selection of clones on the basis of their autologous reactivity. This was especially prominent in clones that were derived from alloauto stimulation.

MS patients generally had more cells in their CSF than control CSF, particularly MS patients in acute exacerbation. Yet cell numbers alone do not explain our results. Several of the control CSF came from individuals with inflammatory CNS disturbances. Lymphocytes from these CSF did not respond to allo-auto antigens as did MS CSF cells. The reasons for this disparity are not known. Lymphoid cells present in CSF during acute or sub-acute nonimmunologic inflammations may have very different immunologic characteristics than do cells drawn to the CSF because of an in situ immune reaction. This regulatory cells or cells responding to altered-self may comprise only a very small fraction of the CSF lymphoid cell population in individuals with nonimmunologic CNS inflammatory reaction. CSF cells from two non-MS did respond similarly to cells from MS patients. (See Appendix for brief clinical summaries.) Patient A was a young woman with viral meningitis that was followed by a transverse myelopathy. Her CSF was obtained during the episode of myelopathy. Patient $B$ was a young man with type I, juvenile onset diabetes mellitus and a multifocal white matter disorder that was similar if not identical to MS. Because type I diabetes may be an autoimmune disease (37) that is sometimes associated with multifocal CNS dysfunction, we could not conclusively diagnose MS in this patient. In any case, the immunological responses that were noted in these CSF suggest that patients with postviral demyelination or multifocal white matter dysfunction that is perhaps related to autoimmune disease may have changes in lymphocyte populations in their CNS that are similar to those seen in MS.

The role of autologously reactive cells in MS CSF is not known. Cells responding in autologous MLR have been shown to possess both helper (20) and suppressor (21) cell function. Autologous recognition is increased in MS patients (22), and this may result in alterations of regulatory lymphocyte subsets. Several laboratories, using both functional and monoclonal antibody assays, have demonstrated a fall in suppressor cells in both peripheral blood $(38,39)$ and CSF $(11)$ during acute exacerbations of the disease. Interestingly, the observations of Damle and Gupta (40) suggest that the presence of autologous reactive cells may be responsible for the decreased percentage of OKT8+ (cytotoxic-suppressor) cells that are noted in the CSF of exacerbating MS patients. These investigators noted that $T$ cells that respond to autologous non- $T$ cells were predominantly of the OKT4+ (helper-inducer) phenotype. The presence of an autologous MLR in MS CSF could thus result in an increased percentage of OKT4+ cells and an apparent fall in OKT $8+$ cells.

All of the clones tested for surface antigen phenotypes were OKT3+, which indicates their $\mathrm{T}$ cell origin. As reported previously with Il-2 dependent bulk cultures of CSF cells (41), most clones expressed the OKT4+ (helper-inducer) phenotype. Of interest were the four clones that expressed both OKT4+ and OKT8+ phenotypes. While double labeling experiments have not yet been done, it is unlikely that these observations are the result of the nonclonality of the cells. In all four instances, $>75 \%$ of the cells expressed both phenotypes, and in two instances, $>90 \%$ of the cells expressed both phenotypes. Too few control cells were tested to determine whether these observations are unique to cells from MS CSF. Cells from control CSF did not grow as well as did cells from MS CSF; thus, insufficient numbers were available for testing. Cells having double markers for both OKT4 and OKT8 defined antigens have been noted in peripheral blood by Wee et al. (42). Merrill et al. (43) noted cells in MS CSF with double markers for IgG and IgM Fc fragments. Whether these latter cells are the same as our OKT $4+8+$ cells remains to be determined.

The rationale for using allogeneic reactivity as a means of identifying cells responsive to altered self antigens is well supported by observations in both mouse $(23,24)$ and man (25), which demonstrated crossreactivity between altered-self antigens and alloantigens. Our observations that large numbers of alloantigen reactive cells are present in MS CSF support our hypothesis that such cells may be participating in an immune reaction to altered (? viral) autologous antigens. It is not clear why in vivo-generated blast cell clones fail to respond to panels of allogeneic cells. Several explanations are possible. 
First, these cells may be responding to a pathogenetically important antigen, and we are not detecting crossreactivity in our system. Second, these cells may be nonspecifically activated by in vivo-generated lymphokines, and have specificities directed against antigens not requiring concurrent recognition of autologous MHC antigens. Third, these cells may be specifically activated, not by altered-self antigens but by antigens on the surfaces of other lymphocytes. In other words, in situ-generated blast cells may be antiidiotypic in their specificity, and thus potentially capable of regulating the responses of cells to altered self antigens. In favor of this latter hypothesis is our observation (unpublished) that MS CSF cells depleted of spontaneous blasts do not respond to allogeneic or autologous stimulation. Spontaneous blast cells thus appear to be important in the regulation of these responses, while they themselves do not exhibit reactivity for these antigens.

Many of our allo-auto stimulated clones were heteroclitic, even though their final selection was on the basis of a response to autologous antigens. In addition, these clones proliferated twice as frequently in response to normal panel cells than MS cells $(P<0.0001)$, even though both cell populations had equal stimulatory capacity in our PLT assays and were similar in their DR phenotypes. No such differences between MS and control panel cells were seen in our auto-auto clone assays. Thus, these observations cannot be explained by alterations in MS non-T cells that were noted by ourselves (44) and others $(45,46)$. We prefer to explain these results by hypothesizing that alloantigen specific suppressor cells were generated during initial culture of CSF lymphocytes with the pool of allogeneic MS lymphocytes (47-50). Upon restimulation with autologous non-T cells, these alloantigen specific suppressors prevented proliferation of cells reactive to autologous antigens shared with the allogeneic MS cells. Cells responding to nonshared antigens could proliferate, and clones derived from such cells would be both heteroclitic and responsive to non-MS alloantigens. Since MS and non-MS panel cells were matched as closely as possible on the basis of DR phenotype, our results suggest a sharing of cell surface antigens in nonrelated MS patients' cells that is not definable on the basis of known serologically determined HLA-DR phenotypes.

Several studies have suggested that immune responses in the CNS are compartmentalized or different from those in the peripheral blood (32-34). In addition, lymphocytes from MS CSF contained higher percentages of $T$ cells than peripheral blood lymphocytes (9), and in some instances had higher or lower percentages of OKT8+ cells than autologous peripheral blood $(11,12)$. Our observations (with the exception of our experiment with CSF \#65), also suggest a compartmentalization of immune responses within the CNS. In general, numbers of peripheral blood $\mathrm{T}$ cells equivalent to those obtained from a CSF sample did not generate as many clones or as many responsive clones as did cells from CSF. In addition, the patterns of responses of peripheral $\mathrm{T}$ cell clones were different from those noted with autologous CSF cells.

The presence of recurring patterns of response among clones that were derived from individual CSF (Figs. 1 and 2) suggest both that the cells in MS CSF are directed to a particular antigen and that an "enrichment" of antigen reactive cells, with resulting decrease in heterogeneity, has occurred. While such responses are probably not unique to patients with MS, they appear to be rare in patients with nonimmunologic inflammations of the CNS. Restricted responses were noted in only one of eight peripheral $\mathrm{T}$ cell samples, making it unlikely that this "oligoclonal" pattern is the result of limited cell numbers. A trivial explanation for our findings would be that the clones tested were all daughters of a single cell that was expanded after secondary stimulation. Our inability to demonstrate recurring patterns of response with clones from peripheral blood lymphocytes would make this possibility similarly less likely. In support of our hypotheses are the observations of Abromson-Leeman and Cantor (51), who recently demonstrated in the mouse that $50 \%$ of clones that responded to the $\alpha$-chain of cow insulin reacted specifically to an allogeneic antigen in the I-E region of the mouse MHC. If the restricted allogeneic responses of clones in MS CSF represent a similar phenomenon, it may be feasible to use these alloantigen reactive cells as probes to detect immune reactions to specific antigens in MS CNS. Experiments to corroborate this interpretation are now in progress.

\section{Appendix}

Patient A. This 33-yr-old woman developed headache, nausea, and vomiting with fever and nucchal rigidity in July, 1982. Lumbar puncture revealed a monocytic pleocytosis. Cultures were all negative and the diagnosis of viral meningitis was made. Recovery from this episode was uneventful.

2 mo later the patient presented with a 6-d history of ascending bilateral lower extremity and perineal numbness that was associated with leg weakness and constipation. Spinal fluid revealed nine mononuclear cells $/ \mathrm{mm}^{3}$ with a protein of $32 \mathrm{mg}$ percent. Myelin basic protein and gamma globulin concentration were in normal range. Oligoclonal bands were present. The patient improved spontaneously without residua.

Patient B. This 29-yr-old male had type I diabetes mellitus diagnosed at age three, and was treated with reasonable success with insulin. Over an 8-yr period he noted left hand tremor and incoordination, decreasing intellectual function, decreased right leg coordination, and unsteady gait. Neurophysiologic tests revealed severe polyneuropathy. Evoked response tests demonstrated bilateral optic nerve dysfunction and bilateral brainstem dysfunction. Spinal fluid examination revealed a mild mononuclear pleocytosis, a mildly elevated total protein (59 mg percent), with an elevated percentage of gamma globulin (14.3\%, normal 7.2 \pm 2.2 ). Myelin basic protein was absent. Oligoclonal bands were present.

\section{Acknowledgments}

The intellectual stimulation and critiques of Dr. Fritz Bach, Dr. Byron Waksman, and Ms. Nancy Reinsmoen are very much appreciated, as is the excellent secretarial help of Ms. Stephanie Daily and the technical assistance of Mr. Michael Hupke. 
This work was supported by grant RG-1516-A-5 from the National Multiple Sclerosis Society.

\section{References}

1. McFarland, H. F., and D. E. McFarlin. 1979. Cellular immune response to measles, mumps, and vaccinia viruses in multiple sclerosis. Ann. Neurol. 6:101-106.

2. Cook, S. D., and P. C. Dowling. 1980. Multiple sclerosis and viruses: an overview. Neurol. (Minneap.). 30:80-91.

3. Martin, J. R. 1981. Herpes simplex virus types 1 and 2 and multiple sclerosis. Lancet. II:777-781.

4. Alter, M. 1981. Multiple sclerosis, herpes viruses and immunity. Lancet. II:1224-1225.

5. Prineas, J. W., and R. G. Wright. 1978. Macrophages, lymphocytes, and plasma cells in the perivascular compartment in chronic multiple sclerosis. Lab. Invest. 38:409-421.

6. Traugott, U., E. L. Reinherz, and C. S. Raine. 1983. Multiple sclerosis: distribution of $\mathrm{T}$ cell subsets within active chronic lesions. Science (Wash. DC). 219:308-310.

7. Allen, J. C., W. Sheremata, and J. B. R. Cosgrove. 1976. Cerebrospinal fluid $\mathrm{T}$ and $\mathrm{B}$ lymphocyte kinetics related to exacerbation of multiple sclerosis. Neurol. (Minneap.). 26:579-583.

8. Levinson, A. I., R. P. Lisak, and B. Zweiman. 1976. Immunological characterization of cerebrospinal fluid lymphocytes: preliminary report. Neurol. (Minneap.). 26:693-695.

9. Kam-Hansen, S. 1980. Distribution and function of lymphocytes from the cerebrospinal fluid and blood in patients with multiple sclerosis. Acta Neurol. Sand. 62(Suppl. 75):1-81.

10. Noronha, A. B. C., D. P. Richman, and B. G. W. Arnason 1980. Detection of in vivo stimulated cerebrospinal fluid lymphocyte by flow cytometry in patients with multiple sclerosis. $N$. Engl. J. Med. 303:713-717.

11. Cashman, N., C. Martin, J.-F. Eizenbaum, J.-D. Degos, and M.-A. Bach. 1982. Monoclonal antibody-defined immunoregulatory cells in multiple sclerosis cerebrospinal fluid. J. Clin. Invest. 70:387392.

12. Hauser, S. L., E. L. Reinherz, C. J. Hoban, S. F. Schlossman and H. L. Weiner. 1983. CSF cells in multiple sclerosis: monoclona antibody analysis and relationship to peripheral blood $\mathrm{T}$ cell subsets. Neurol. (Cleveland). 33:575-579.

13. Merrill, J. E., R. H. Gerner, L. W. Myers, and G. W. Ellison 1983. Regulation of natural killer cell cytotoxicity by prostaglandin $E$ in the peripheral blood and spinal fluid of patients with multiple sclerosis and other neurological diseases. Part 1. Association between amount of prostaglandin produced, natural killer, and endogenous interferon. 1983. J. Neuroimmunol. 4:223-237.

14. Lisak, R. P., and B. Zweiman. 1977. In vitro cell-mediated immunity of cerebrospinal fluid lymphocytes to myelin basic protein in primary demyelinating diseases. N. Engl. J. Med. 297:850-853.

15. Reunanen, M., A. Salmi, J. Ilonen, and E. Herva. 1980. Proliferation of multiple sclerosis cerebrospinal fluid lymphocytes after stimulation with measles virus antigens. Acta Neurol. Scand. 62:293299.

16. Kam-Hansen, S., H. Link, A. Fryden, and E. Moller. 1979. Reduced in vitro response of CSF lymphocytes to mitogen stimulation in CSF lymphocytes to mitogen stimulation in multiple sclerosis. Scand. J. Immunol. 10:161-169.

17. Kam-Hansen, S., R. Anderson, and H. Link. 1983. Cerebrospinal fluid lymphocytes from patients with multiple sclerosis and aseptic meningoencephalitis respond in mixed lymphocyte culture. $J$. Neuroimmunol. 5:67-81.

18. Zinkernagel, R. M., and P. C. Doherty. 1974. Restriction of in vitro $\mathrm{T}$ cell mediated cytotoxicity in lymphocytic choriomeningitis within a syngeneic or semi-allogeneic system. Nature (Lond.). 248:701702.

19. Ho, H.-Z., J. L. Tiwari, R. W. Haile, P. I. Terasaki, and N. E. Morton. 1982. HLA linked and unlinked determinants of multiple sclerosis. Immunogenetics. 15:509-517.

20. Hausman, P. B., and J. D. Stobo. 1979. Specificity and function of a human autologous reactive T cell. J. Exp. Med. 149:1537-1542.

21. Smith, J. B., and R. P. Knowlton. 1979. Activation of suppressor $\mathrm{T}$ cells in human autologous mixed lymphocyte culture. J. Immunol. 123:419-422.

22. Birnbaum, G., and L. Kotilinek. 1981. Autologous lymphocyte proliferation in multiple sclerosis and the effect of intravenous ACTH Ann. Neurol. 9:439-446.

23. Bevan, M. J. 1977. Killer cells reactive to altered-self antigens can also be alloreactive. Proc. Natl. Acad. Sci. USA. 74:2094-2098.

24. Sredni, B., and R. H. Schwartz. 1980. Alloreactivity of an antigen-specific T cell clone. Nature (Lond.). 287:855-857.

25. Gaston, J. S. H., A. B. Rickinson, and M. A. Epstein. 1983. Cross-reactivity of self-HLA-restricted Epstein-Barr virus-specific cytotoxic T lymphocytes for allo-HLA determinants. J. Exp. Med. 158:1804-1821.

26. Poser, C. M., D. W. Paty, L. Scheinberg, W. I. McDonald, F. A. Davis, G. C. Ebers, K. P. Johnson, W. A. Sibley, D. H. Silberberg, and W. W. Tourtellotte. 1983. New diagnostic criteria for multiple sclerosis: guidelines for research protocols. Ann. Neurol. 13:227-231.

27. Kozak, R. W., C. E. Moody, L. Staiano-Coico, and M. E. Weksler. 1982. Lymphocyte transformation induced by autologous cells. XII. Quantitative and qualitative differences between human autologous and allogeneic reactive $\mathrm{T}$ lymphocytes. J. Immunol. 128:1723-1727.

28. Inouye, H., J. A. Hank, B. J. Alter, and F. H. Bach. 1980. TCGF production for cloning and growth of functional human $T$ lymphocytes. Scand. J. Immunol. 12:149-154.

29. Bach, F. H., B. J. Alter, M. B. Widmer, M. Segall, and B. Dunlap. 1981. Cloned cytotoxic and non-cytotoxic lymphocytes in mouse and man: their reactivities and a large cell surface membrane protein (LMP) differentiation marker system. Immunol. Rev. 54:5-26.

30. Reinsmoen, N., and M. Segall. 1981. Primed LD (lymphocyte) typing (PLT). AACHT Laboratory Manual. A. A. Zachary and W. E. Braun, editors. IV-3-1. American Association of Clinical Histocompatibility Testing, New York. IV-3-1-IV-3-12.

31. Meuer, S. C., S. F. Schlossman, and E. Reinherz. 1980. Clonal analysis of human cytotoxic $\mathrm{T}$ lymphocytes: $\mathrm{T} 4+$ and $\mathrm{T} 8+$ effector $\mathrm{T}$ cells recognize products of different major histocompatibility complex regions. Proc. Natl. Acad. Sci. USA. 79:4395-4399.

32. Fleischer, B., and H. W. Kreth. 1983. Clonal analysis of HLArestricted virus-specific cytotoxic $\mathrm{T}$ lymphocytes from cerebrospinal fluid in mumps meningitis. J. Immunol. 130:2187-2190.

33. Link, H., and R. Muller. 1971. Immunoglobulins in multiple sclerosis and infections of the nervous system. Arch. Neurol. 25:326344.

34. Ukkonen, P., M.-L. Rasanen, Jr., E.-M. Salonen, and K. Penttinen. 1981. Local production of mumps IgG and IgM antibodies in the cerebrospinal fluid of meningitis patients. J. Med. Virol. 8:257265.

35. Narayan, O., D. E. Griffin, and J. E. Clements. 1978. Virus mutation during "slow infection": temporal development and charac- 
terization of mutants of Visna virus recovered from sheep. J. Gen. Virol. 41:343-352.

36. Horta-Barbosa, L., L. R. Hamilton, T. Wittig, D. A. Fucillo, J. L. Sever, and M. L. Vernon. 1971. Subacute sclerosing panencephalitis: isolation of suppressed measles virus from lymph node biopsies. Science (Wash. DC). 173:840-841.

37. Cahill, G. F., Jr., and H. O. McDevitt. 1981. Insulin-dependant diabetes mellitus: the initial lesion. N. Engl. J. Med. 304:1454-1465.

38. Antel, J. P., D. P. Richman, M. E. Medof, and B. G. W. Arnason. 1978. Lymphocyte function and the role of regulator cells in multiple sclerosis. Neurology. 28:106-110.

39. Reinherz, E. L., H. L. Weiner, S. L. Hauser, J. A. Cohen, J. A. Distaso, and S. F. Schlossman. 1980. Loss of suppressor T cells in active multiple sclerosis. Analysis with monoclonal antibodies. New Engl. J. Med. 303:125-129.

40. Damle, N. K., and S. Gupta. 1982. Autologous mixed lymphocyte reaction in man. V. Functionally and phenotypically distinct human $T$ cell sub-populations respond to non- $T$ and activated $T$ cells in AMLR. Scand. J. Immunol. 16:59-68.

41. Burns, J. B., B. Zweiman, and R. P. Lisak. 1981. Long term growth in vitro of human cerebrospinal fluid $\mathrm{T}$ lymphocytes. J. Clin. Immunol. 1:195-200.

42. Wee, S. L., L. K. Chen, G. Strassman, and F. H. Bach. 1982. Helper cell independent cytotoxic clones in man. J. Exp. Med. 156:1854-1859.

43. Merrill, J. E., G. Biberfeld, S. Landen, A. Siden, and E. Norrby. 1980. Identification of three FcR-positive $T$ cell subsets $\left(T_{G}, T_{M}\right.$ and $\mathrm{GM}$ ) in the cerebrospinal fluid of multiple sclerosis patients. Clin. Exp. Immunol. 42:345-354.
44. Reder, A., and G. Birnbaum. 1983. B-cell differentiation in multiple sclerosis and the effect of intravenous ACTH. Neurology. 33:442-446.

45. Levitt, D., N. B. Griffin, and M. L. Egan. 1980. Mitogen induced plasma cell differentiation in patients with multiple sclerosis. J. Immunol. 124:2117-2121.

46. Goust, J. M., E. L. Hogan, and P. Arnaud. 1982. Abnormal regulation of IgG production in multiple sclerosis. Neurology. 32:22834.

47. Hirschberg, H., and E. Thorsby. 1977. Activation of human suppressor cells in MLC. Scand. J. Immunol. 6:809-815.

48. Engleman, E. G., A. J. McMichael, M. E. Batey, and H. O. McDevitt. 1978. A suppressor $T$ cell of the mixed lymphocyte reaction specific for the stimulating alloantigen. Evidence that identity at HLAD between suppressor and responder is required for suppression. $J$. Exp. Med. 147:137-146.

49. Sheehy, M. J., C. Mawas, and D. Charnot. 1979. Specific inhibition of human lymphocyte responses by primed autologous lymphocytes. I. Evaluation of MLR inhibition as a model for suppression. J. Immunol. 122:2198-2203.

50. Sasportes, M., E. Wollman, D. Cohen, E. Carosella, A. Bensussan, D. Fradelizi, and J. Dansset. 1980. Suppression of the human allogeneic response in vitro with primed lymphocytes and suppressive supernates. J. Exp. Med. 152:270s-283s.

51. Abromson-Leewan, S. R., and H. Cantor. 1983. Specificity of $\mathrm{T}$ cell clones for antigen and autologous major histocompatibility complex products determines specificity for foreign major histocompatibility complex products. J. Exp. Med. 158:428-437. 